\title{
Research of the origin of a particular Tunisian group using a physical marker and Alu insertion polymorphisms
}

\author{
Wifak El Moncer ${ }^{1}$, Raoudha Bahri ${ }^{1}$, Esther Esteban ${ }^{2}$, Bouthaina Abdenni-Guenounou $^{3}$, Pedro Moral ${ }^{2}$, \\ Jemni Ben Chibani ${ }^{4}$ and Hassen Chaabani ${ }^{1}$ \\ ${ }^{1}$ Laboratory of Human Genetics and Anthropology, Faculty of Pharmacy, University of Monastir, \\ Monastir, Tunisia. \\ ${ }^{2}$ Secció d'Antropologia, Departament de Biologia Animal, Universitat de Barcelona, Barcelona, Spain. \\ ${ }^{3}$ Centre Régional de Transfusion Sanguine de Gabès, Gabès, Tunisia. \\ ${ }^{4}$ Laboratory of Biochemistry, Faculty of Pharmacy, University of Monastir, Monastir, Tunisia.
}

\begin{abstract}
The aim of this study was to show how, in some particular circumstances, a physical marker can be used along with molecular markers in the research of an ancient people movement. A set of five Alu insertions was analysed in 42 subjects from a particular Tunisian group (El Hamma) that has, unlike most of the Tunisian population, a very dark skin, similar to that of sub-Saharans, and in 114 Tunisian subjects (Gabes sample) from the same governorate, but outside the group. Our results showed that the El Hamma group is genetically midway between sub-Saharan populations and North Africans, whereas the Gabes sample is clustered among North Africans. In addition, The A25 Alu insertion, considered characteristic to sub-Saharan Africans, was present in the El Hamma group at a relatively high frequency. This frequency was similar to that found in sub-Saharans from Nigeria, but significantly different from those found in the Gabes sample and in other North African populations. Our molecular results, consistent with the skin color status, suggest a sub-Saharan origin of this particular Tunisian group.
\end{abstract}

Key words: Tunisian population, El Hamma group, skin color, Alu insertion polymorphisms, people movement history.

Received: October 29, 2010; Accepted: March 23, 2011.

\section{Introduction}

Before the $20^{\text {th }}$ century, anthropologists were interested in measurements of observable physical characters, such as skin color and size and shape of the skull. More recently, criticisms were directed to some of these classic anthropologists who classified humans into races by setting limits in the continuous variations of physical characteristics (e.g. Jones, 1981; Langaney, 1984). During the $20^{\text {th }}$ century, the advances in heredity studies and, later on, in molecular genetic technologies have allowed anthropologists to study the polymorphisms of molecular characters at the protein and subsequently the DNA level. Although, during the last two decades, innumerable data on various kinds of DNA have rapidly accumulated, they alone cannot elucidate all problems and questionable considerations regarding our evolutionary history. Therefore, many authors have attempted to complete these molecular data by other kinds of evidence originated from cultural/social fields such as language (e.g. Cavalli-Sforza et al., 1988; Chaabani

Send correspondence to Hassen Chaabani. Laboratory of Human Genetics and Anthropology, Faculty of Pharmacy, University of Monastir, $5000 \quad$ Monastir, Tunisia. E-mail: hassenchaabani@gmail.com. et al., 2000). Moreover, in 2002, Relethford, going back to the measurement of observable physical characters, showed that the analysis of craniometric variation provides results on human genetic diversity within and among populations, similar to those obtained from genetic markers and DNA polymorphisms, while the analysis of skin color variation gives the opposite results. In fact, the worldwide distribution of human skin color is correlated with the global distribution of ultraviolet radiation, suggesting past selection for dark skin near the equator and for light skin at greater latitudes. Thus, variations in skin color are adaptive, and their general analysis tells little about global population history and relationships (Jablonski and Chaplin, 2000; Relethford, 2002). However, in this study we illustrate how, under particular circumstances, skin color can be used, along with molecular markers, to enlighten ancient population movements.

The current general Tunisian population is composed mainly of Berbers, natives of North Africa, mixed with some peoples originated from the different civilizations that have settled in this region in historical times, particularly Arabs who, unlike their precedents, settled permanently in Tunisia following their substantial expansion in the $7^{\text {th }}$ century. Berbers and Arabs accepted mixed mar- 
riages and eventually became a common sole population, except for a few groups of Berbers, geographically located on the top of small mountains, such as Takrouna and Jeradou in the north of the country, and Douirete-Chenini in the extreme south, as well as a group living in the "Gallala" region of the Djerba Island (Chaabani and Cox, 1988) (Figure 1). These Berber groups are small, often not exceeding 4000 individuals. Although known as Berber communities, they only know a few words of their ancestral Berber language and have a certain admixture with peoples outside their group. In addition to these Berber groups, in the south of Tunisia there are some dispersed families and groups that, in contrast to the general Tunisian population, have a very dark skin (type VI, Weller et al., 2008). Only two groups could be considered to be entities large enough to be studied: the "El Hamma group" that lives in the El Hamma village and a group living on the Djerba Island, where a Jewish community lives too (Figure 1). The aim of this study was to research and discuss the origin of the El Hamma group, using molecular data from Alu insertion polymorphisms and taking into account a physical trait, the skin color.

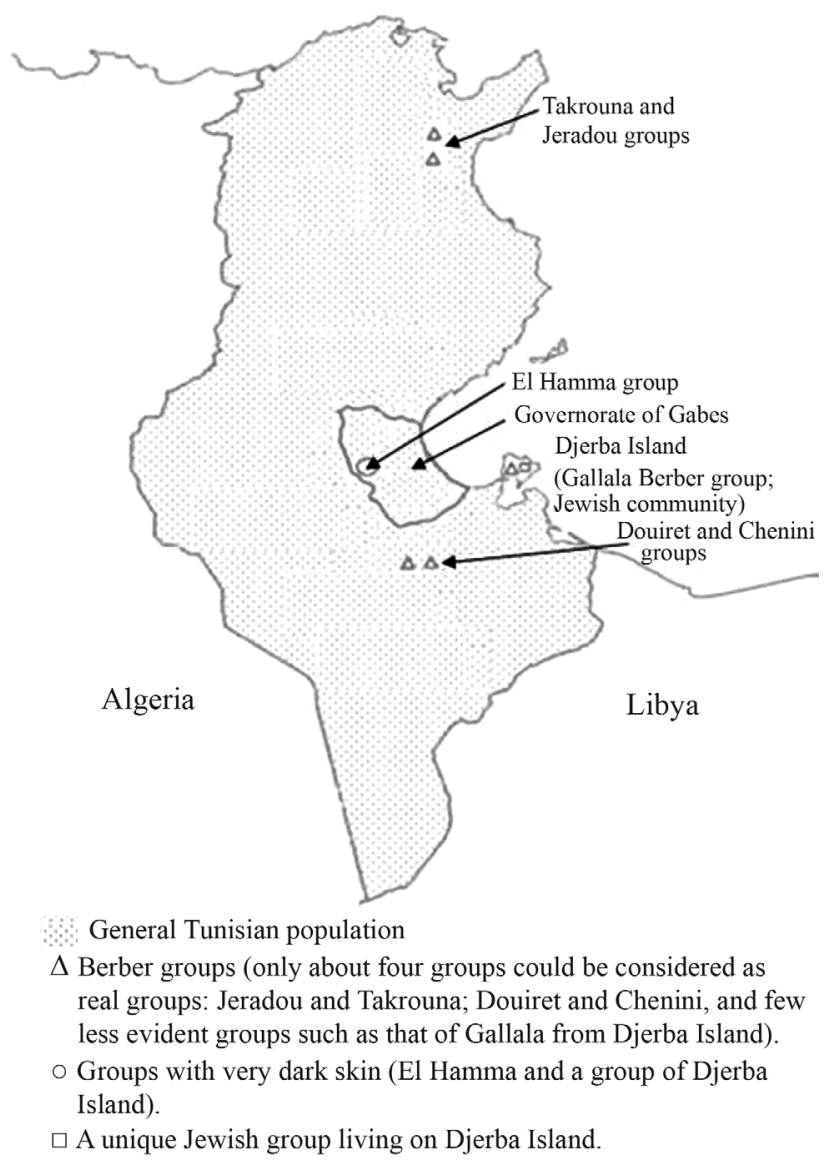

Figure 1 - Tunisian groups which remained rather isolated and maintained a relatively high endogamy. The general Tunisian population and all different groups share a single Muslim Arab culture, except for the Jews which have another religion, although they speak Arab and they customs in general similar to the other inhabitants of the Djerba Island.
The Alu insertion markers were selected particularly for their stability, low mutation rate and known ancestral state. In fact, Alu insertions of short interspersed nuclear elements (SINEs) represent more than $10 \%$ of the human genome. Their polymorphisms consist of the presence or absence of an Alu element at a particular human chromosomal location. Apparently they are selectively neutral and not subject to loss or rearrangement. In addition, all loci carrying one of these human Alu insertions derive from a unique event and hence are identical by descent. Their ancestral state can be reasonably inferred to be the absence of the insertion. The direction of mutational change is therefore the gain of the Alu element at a particular locus (for review, see Batzer et al., 1994). All these distinctive features make human Alu insertion polymorphisms a good tool for studying the genetic differentiations of human populations worldwide.

\section{Subjects and Methods}

Blood samples were collected from 42 individuals belonging to a particular Tunisian group, "El Hamma", composed of about 2000 individuals with very dark skin, comparable to type VI of the Fitzpatrick (1975) classification of skin types. In order to avoid the subjectivity of classifying skin types into six categories as Fitzpatrick proposed, the skin tone of the "El Hamma" group was determined by visual inspection in the presence of four volunteers, considered as controls, from a sub-Saharan country (Nigeria). All sampled "El Hamma" individuals showed a skin type comparable to that of the sub-Saharan African controls. This group takes its name from a village that belongs to the governorate of Gabes, located in southeast Tunisia (Figure 1). Additionally, blood samples of 114 individuals outside this group but from the same governorate, the Gabes sample, were collected as controls. These individuals have a skin tone similar to that of other Mediterranean peoples. All sampled individuals were unrelated, healthy donors and signed an informed consent form approved by the Ethics Committee of the University involved in the study. As endogamy is relatively high in the El Hamma group, we selected only individuals (42) which we were sure to be unrelated.

Genomic DNA was extracted from blood cells by standard phenol-chloroform techniques. Five Alu insertions (A25, TPA25, APO-AI, PV92, ACE) located on four different chromosomes (respectively $\mathrm{n}^{\circ} 8,11,16$ and 17) were typed by PCR amplification, using primers described previously (Batzer and Deininger, 1991). The amplification conditions were: a preliminary step of $94{ }^{\circ} \mathrm{C}$ for five minutes; many subsequent cycles consisting of denaturing at $94{ }^{\circ} \mathrm{C}$ for $1 \mathrm{~min}$, followed by annealing at different temperatures, depending on the markers (Stoneking et al., 1997), for $1 \mathrm{~min}$; an extension cycle at $72{ }^{\circ} \mathrm{C}$ for $2 \mathrm{~min}$; and a final elongation step at $72{ }^{\circ} \mathrm{C}$ for $5 \mathrm{~min}$. Positive and negative 
controls for the polymorphisms under study were included in all PCR runs.

Allele frequencies were estimated by direct counting. Hardy-Weinberg equilibrium was assessed by an exact test (Guo and Thompson, 1992). Heterozygosity values were calculated according to M. Nei's formula (Saitou and Nei, 1987) and compared between our two samples were compared through a Mann-Whitney $U$ test. Interpopulation measures of gene diversity between the Gabes and El Hamma groups were assessed by means of $\mathrm{G}_{\mathrm{ST}}$ values using the Genetix 4.05 software (Belkhir K et al., 1996-2004). Population relationships were determined by an exact population differentiation test, using the Arlequin v 2.0 package (Schneider et al., 2000), and genetic relationships were depicted by a principal components (PC) plot based on the analysis of the R-matrix (Harpending and Jenkins, 1973). Thirteen populations were considered in comparative analyses; they are presented with their respective geographic location in Figure 2. Their corresponding Alu insertion frequencies were obtained from previous studies (Stoneking et al., 1997; Comas et al., 2000; Garcia-Obregón et al., 2006; Bahri et al., 2008; González-Pérez et al. 2010).

\section{Results}

Alu allele frequencies for the five loci examined are shown in Table 1. All genotype distributions were in agreement with the Hardy-Weinberg equilibrium after applying the Bonferroni correction. The highest allele frequency corresponds to the APO-A1 locus ( 0.862 in Gabes, and 0.756 in El Hamma). The lowest frequencies were observed for the A25 locus in Gabes (0.111) and for the PV92 locus in El

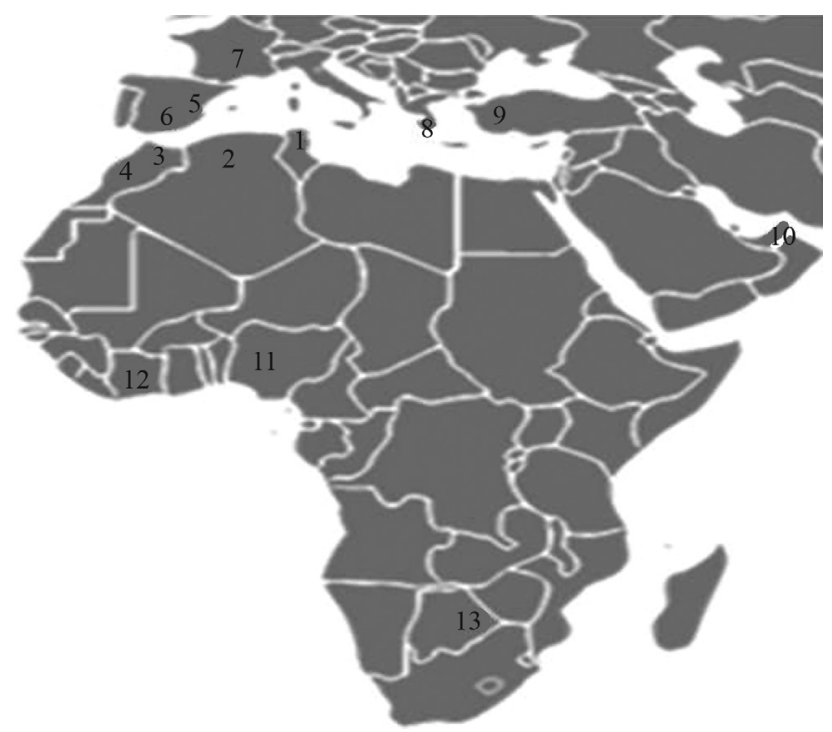

Figure 2 - Geographical location of population samples used for comparisons. 1: Tunisia (general population, Gabes sample, and El Hamma group); 2: Algeria; 3: North Morocco; 4: West Morocco; 5: Valencia (Spain); 6: Andalusia (Spain); 7: France; 8: Cyprus (Greek Cypriots); 9: Cyprus (Turk Cypriots); 10: United Arab Emirates; 11: Nigeria; 12: Ivory Coast; 13: Sotho.
Hamma (0.203). Table 1 also shows the heterozygosity values by locus and population. The highest value corresponds to Alu TPA 25 in both samples (0.505 in El Hamma, and 0.501 in Gabes) and the lowest value for Alu PV92 (0.328) was observed in the El Hamma sample, and for Alu A25 (0.198) in Gabes. The El Hamma sample showed a mean heterozygosity value $(0.405 \pm 0.072)$ that was somewhat higher than that observed in Gabes $(0.339 \pm 0.122)$, but the difference was not statistically significant (MannWhitney's U test: $p=0.548$ ).

The allele frequency distributions in Gabes and El Hamma were compared for the five Alu insertions, but only the A25 locus $(\mathrm{p}<0.05)$ showed a statistically significant difference. Thus, the $\mathrm{G}_{\mathrm{ST}}$ values between Gabes and El Hamma (Table 1) were low for all loci except Alu A25 $\left(\mathrm{G}_{\mathrm{ST}} 2.8 \%\right)$.

Comparing our two samples with the general Tunisian population (Bahri et al., 2008), the Alu frequency distribution in our samples was found to be significantly different from that of the general Tunisian population. This difference is attributed to loci PV92 ( $\mathrm{p}=0.005)$, A25 $(\mathrm{p}=0.005)$ and APO-A1 $(\mathrm{p}<0.001)$ in the El Hamma group, and to loci APO-A1 $(\mathrm{p}<0.001)$ and PV92 $(\mathrm{p}<0.001)$ in the Gabes sample.

We also used the exact test to compare our two samples with sub-Saharan populations on one hand, and North African populations (Algeria, North Morocco and West Morocco) on the other. For the El Hamma group, the exact test indicated a more marked differentiation from the North

Table 1 - Alu insertion frequencies, heterozygosity $(\mathrm{H}), \mathrm{G}_{\mathrm{ST}}$ values and exact test of genetic differentiation between El Hamma and Gabes samples.

\begin{tabular}{|c|c|c|c|c|}
\hline Locus & El Hamma (N = 42) & $\begin{array}{l}\text { Gabes sample } \\
(\mathrm{N}=114)\end{array}$ & $\mathrm{G}_{\mathrm{ST}}$ & $\begin{array}{l}\text { Exact test } \\
\text { probability }\end{array}$ \\
\hline \multicolumn{5}{|l|}{ A25 } \\
\hline $\mathrm{Alu}^{+}$ & $0.250 \pm 0.047$ & $0.111 \pm 0.024$ & 0.0283 & 0.041 \\
\hline $\mathrm{H}$ & $0.379 \pm 0.024$ & $0.198 \pm 0.067$ & & \\
\hline \multicolumn{5}{|l|}{ TPA25 } \\
\hline $\mathrm{Alu}^{+}$ & $0.475 \pm 0.056$ & $0.520 \pm 0.034$ & 0.0023 & 0.802 \\
\hline $\mathrm{H}$ & $0.505 \pm 0.024$ & $0.501 \pm 0.037$ & & \\
\hline \multicolumn{5}{|l|}{$\mathrm{ACE}$} \\
\hline $\mathrm{Alu}^{+}$ & $0.319 \pm 0.054$ & $0.245 \pm 0.031$ & 0.0013 & 0.360 \\
\hline $\mathrm{H}$ & $0.440 \pm 0.002$ & $0.371 \pm 0.024$ & & \\
\hline \multicolumn{5}{|l|}{ APO AI } \\
\hline $\mathrm{Alu}^{+}$ & $0.756 \pm 0.046$ & $0.862 \pm 0.026$ & 0.0063 & 0.135 \\
\hline $\mathrm{H}$ & $0.345 \pm 0.041$ & $0.239 \pm 0.066$ & & \\
\hline \multicolumn{5}{|l|}{ PV92 } \\
\hline $\mathrm{Alu}^{+}$ & $0.203 \pm 0.048$ & $0.259 \pm 0.035$ & 0.0025 & 0.990 \\
\hline $\mathrm{H}$ & $0.328 \pm 0.043$ & $0.387 \pm 0.018$ & & \\
\hline Mean $\mathrm{H}$ & $0.405 \pm 0.072$ & $0.339 \pm 0.122$ & & \\
\hline
\end{tabular}


African than from the sub-Saharan populations. In fact, the comparison of the El Hamma group with the North African populations showed seven statistically significant differences $(0.01<p<0.05)$ over a total of 15 cases, while that with sub-Saharan populations showed only three statistically significant differences over a total of 15 possible tests. Namely, only the population of the Ivory Coast presented a significant difference from the El Hamma group for TPA $25(\mathrm{p}=0.004)$, PV $92(\mathrm{p}=0.021)$ and APO-A1 $(\mathrm{p}<0.001)$, while no significant differences were found between the El Hamma group and the two other sub-Saharan populations (from Nigeria and South Africa). On the other hand, the comparisons of the Gabes group with North African and sub-Saharan African populations showed the opposite trend: fewer differences from the North Africans (four significant cases over a total of $15, p=0.021$ ) than from the sub-Saharan populations (eight out of 15 significant cases, $\mathrm{p}<0.001$ ).

We further estimated the genetic position of the El Hamma group amongst 13 populations from sub-Saharan Africa, the Mediterranean and the Middle East (Figure 2) by performing a $\mathrm{PC}$ analysis (Figure 3 ). The first two axes accounted for $95.1 \%$ of the total genetic variance. Populations were grouped according to geography: sub-Saharan and non-sub-Saharan populations are clearly separated along the first axis (with $79.70 \%$ of the total variance), while non-sub-Saharan African populations are spread along the second axis (15.4\%). On the first axis, the El Hamma group shows an intermediate position among the two main population clusters, whereas the Gabes sample is clustered among the North African populations.

\section{Discussion}

This study is a contribution for a better knowledge of the origin of a particular Tunisian population group, the "El Hamma", showing how a physical marker can be used together with molecular markers to explain ancient people relationships. In this group, as in the other few Tunisian groups (Figure 1), a relatively high endogamy has led to the

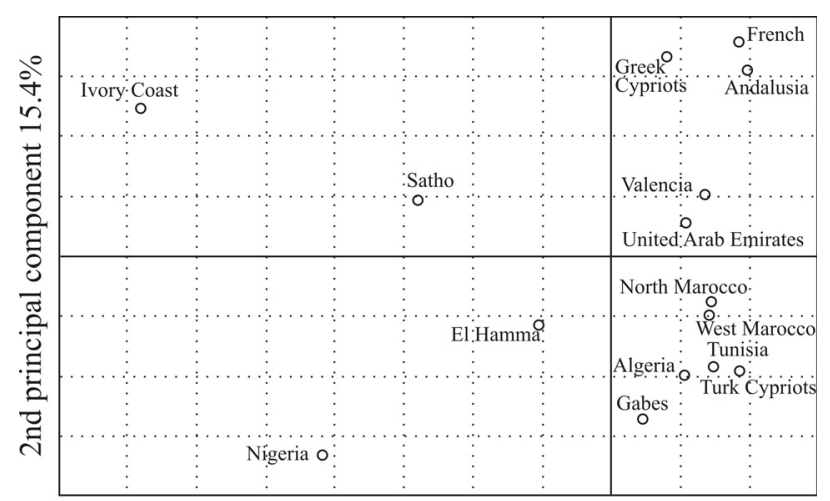

1st principal component $79.70 \%$

Figure 3 - PC plot based on the variation of five Alu insertion polymorphisms among several populations. maintenance of a certain ethnic homogeneity. As, unlike the general Tunisian population, all individuals of this group have a skin color similar to that of the majority of sub-Saharan Africans, it occurred to us that this group might have a sub-Saharan origin.

In fact, variations in skin color are adaptive and are related to the regulation of ultraviolet (UV) radiation penetration in the integument (Jablonski and Chaplin, 2000). The correlation existing between skin color and climate could lead to a convergent evolution of populations living in similar climates, enough to mask the genetic relationships of human populations. Thus, it is evident that we cannot reconstruct our general evolutionary history based on an analysis of the variation of this physical character. However, during our evolutionary history, the adaptation process regarding skin color occurred over a very long time. In addition, a change in color tone could be negligible when humans migrate to a location not too distant from their place of origin and receive there a similar degree of sunlight, as in the case of migration between the northern sub-Saharan countries and the extreme south of Tunisia.

In light of all these considerations, along with the fact that the neighboring sub-Saharan populations have very dark skin, the hypothesis of a sub-Saharan origin of the El Hamma group seems plausible. Our investigation of the unrelated families in our study sample supports this hypothesis. In fact, the members of these families only know that their ancestors came from southern regions of Libya and Algeria since about hundreds of years ago. This is compatible with the fact that the extreme south of Tunisia is in continuity with Libya and Algeria (Figures 1 and 2), which shared their southern borders with neighboring subSaharan countries. So, the assumed ancestors of the El Hamma group likely came from sub-Saharan countries and stayed in the south of Libya or Algeria for enough generations as to forget their first origin.

Our results on Alu insertion markers, which also support this hypothesis, suggest a relevant sub-Saharan African contribution to the gene pool of the current El Hamma inhabitants. In fact, although they live in the south of Tunisia, this group occupies a midway position between subSaharan populations and North Africans in the PC plot based on genetic distances. On the other hand, the Gabes inhabitants, living in the same governorate, cluster together with the general Tunisian population and other North African groups (Figure 3). Furthermore, the A25 Alu insertion, observed at high frequencies in sub-Saharan Africans, is also present in the El Hamma group at a relatively high frequency, similar to that found in sub-Saharans from Nigeria, but significantly different from that observed in the Gabes sample and in the general Tunisian population (Table 2). As shown therein, the relatively high frequency of the A25 Alu insertion could be considered as characteristic to subSaharan African samples: the Alu A25 frequency decreases from southern Africa towards the north; therefore, it is evi- 
Table 2 - Distribution of A25 Alu frequencies in populations from different countries.

\begin{tabular}{llcc}
\hline Populations & & $\mathrm{N}$ & Alu A25 frequencies \\
\hline Sub-Saharan Africa & & 48 & 0.390 \\
& South Africans (Sotho) & 118 & 0.352 \\
& Ivory Coast population & 11 & 0.220 \\
\hline Nigerians & & \\
\hline Tunisia & El Hamma group & 42 & 0.250 \\
& Gabes (Controls) & 114 & 0.106 \\
& Tunisians (general population) & 121 & 0.109 \\
\hline North Morocco & & 111 & 0.113 \\
\hline Valencia (Spain) & & 106 & 0.104 \\
\hline United Arab Emirates & & 42 & 0.120 \\
\hline
\end{tabular}

dently low in all analyzed populations from Europe, Middle East and North Africa, except for the El Hamma group. Although these molecular results support a sub-Saharan origin of the El Hamma group, they should be confirmed by further analyses based on molecular markers previously described as highly discriminating between sub-Saharan and non sub-Saharan African populations (El Moncer et al., 2010; González-Pérez et al., 2010).

Our results provided additional information concerning a slight but significant heterogeneity between the Gabes sample (from the Gabes governorate located in the south of Tunisia) and the general Tunisian population. This slight yet significant heterogeneity between the extreme southern regions and the rest of Tunisia is in accordance with recent more detailed results (El Moncer et al., 2010).

Harpending and Eller (1999) proposed that, in addition to molecular neutral markers, other anthropological traits like language and external physical appearance might provide relevant information for understanding human evolutionary relationships. If cultural markers such as historical data and language have already been used in several molecular studies, the physical markers are not yet sufficiently used. Here, we present a case showing how, in some particular circumstances, a physical marker can be used along with molecular markers to provide information about an ancient population movement. In fact, the high degree of network complexity of the current world population genetic relationships makes it necessary to use a combination of many categories of markers.

\section{Acknowledgments}

We thank all the anonymous people for their participation in the study. This research was supported in part by the Tunisian Ministry of Higher Education within the research unit 05/UR/09-04.

\section{References}

Bahri R, Esteban E, Moral P and Chaabani H (2008) New insights into the genetic history of Tunisians: Data from Alu insertion and apolipoprotein E gene polymorphisms. Ann Hum Biol 35:22-33.

Batzer MA and Deininger PL (1991) A human-specific subfamily of Alu sequences. Genomics 9:481-487.

Batzer MA, Stoneking M, Alegria-Hartman M, Bazan H, Kass DH, Shaikh TH, Novick GE, Ionnou PA, Sheer WD, Herrera RJ et al. (1994) African origin of human-specific polymorphic Alu insertions. Proc Natl Acad Sci USA 91:1228812292.

Belkhir K, Borsa P, Chikhi L, Raufaste N and Bonhomme F (1996-2004) GENETIX 4.05, logiciel sous Windows TM pour la génétique des populations. Laboratoire Génome, Populations, Interactions, CNRS UMR 5000, Université de Montpellier II, Montpellier, France.

Cavalli-Sforza LL, Piazza A, Menozzi P and Mountain J (1988) Reconstruction of human evolution: Bring together genetic archaeological and linguistic data. Proc Natl Acad Sci USA 85:6002-6006.

Chaabani H and Cox DW (1988) Genetic characterization and origin of Tunisian Berbers. Hum Hered 38:308-316.

Chaabani H, Sanchez-Mazas A and Sallami SF (2000) Genetic differentiation of Yemeni people according to Rhesus and GM polymorphisms. Ann Genet 43:155-162.

Comas D, Calafell F, Benchemsi N, Helal A, Lefranc G, Stonecking M, Batser MA, Bertranpetit J and Sajantila A (2000) Alu insertion polymorphisms in NW Africa and Iberian Peninsula: Evidence for strong genetic boundary though the Gibraltar Straits. Hum Genet 107:312-319.

El Moncer W, Esteban E, Bahri R, Gayà-Vidal M, CarrerasTorres R, Athanasiadis G, Moral P and Chaabani H (2010). Mixed origin of the current Tunisian population from the analysis of $A l u$ and $A l u /$ STR compound systems. J Hum Genet 55:827-833.

Fitzpatrick TB (1975). Soleil et peau. J Med Esthet 2:33034.

Garcia-Obregon S, Alfonso-Shandez MA, Perez-Miranda AM, Vidales C, Arroyo D and Pena JA, (2006) Genetic position 
of Valencia (Spain) in the Mediterranean basin according to Alu insertions. Am J Hum Biol 18:187-195.

González-Pérez E, Esteban E, Via M, Gayà-Vidal M, Athanasiadis G, Dugoujon JM, Luna F, Mesa MS, Fuster V, Kandil $\mathrm{M}$ et al. (2010) Population relationships in the Mediterranean revealed by autosomal genetic data (Alu and Alu/STR compound systems). Am J Phys Anthrop 141:430-439.

Guo S and Thompson E (1992) Performing the exact test of Hardy-Weinberg proportion for multiple alleles. Biometrics 48:361-372.

Harpending HC and Eller E (1999) Human diversity and its history. In: Kato M and Takahata N (eds) Biodiversity. Springer-Verlag, Tokyo, pp 301-314.

Harpending HC and Jenkins T (1973) Genetic distance among southern African populations. In: Crawford MH and Workman PL (eds) Methods and Theories in Anthropological Genetics. Albuquerque University, Albuquerque, pp 177199.

Jablonski NG and Chaplin G (2000) The evolution of skin coloration. J Hum Evol 39:57-106.

Jones JS (1981) How different are human race? Nature 293:188190
Langaney A (1984) La nouvelle démographie de l'évolution. Population 39:587-606.

Relethford JH (2002) Apportionment of global human genetic diversity based oncraniometrics and skin color. Am J Phys Anthropol 118:393-398.

Saitou N and Nei M (1987) The neighbor-joining method: A new method for reconstructing phylogenetic trees. Mol Biol Evol 4:406-425.

Schneider S, Roessli D and Excoffier L (2000) Arlequin: A software for population genetics data analysis, v. 2.0. Genetics and Biometry Laboratory, Department of Anthropology and Ecology, University of Geneva.

Stoneking M, Fontius JJ, Cliford SL, Soodyall H, Arcott SS, Nilmani S, Jenkins T, Tahir MA, Deininger PL and Batzer M (1997) Alu insertion polymorphisms and human evolution: Evidence for a large population size in Africa. Genome Res 7:1061-1071.

Weller R, Hunter J, Savin J and Dahl M (2008) Clinical Dermatology. 4th edition. Blackwell Publishing, Malden, 268 pp.

Associate Editor: Francisco Mauro Salzano

License information: This is an open-access article distributed under the terms of the Creative Commons Attribution License, which permits unrestricted use, distribution, and reproduction in any medium, provided the original work is properly cited. 